University of New Orleans

ScholarWorks@UNO

7-1994

\title{
Direct relation between Fresnel's interface reflection coefficients for the parallel and perpendicular polarizations: erratum 2
}

R. M.A. Azzam

University of New Orleans, razzam@uno.edu

Follow this and additional works at: https://scholarworks.uno.edu/ee_facpubs

Part of the Electrical and Electronics Commons, and the Optics Commons

\section{Recommended Citation}

R. M. A. Azzam, "Direct relation between Fresnel's interface reflection coefficients for the parallel and perpendicular polarizations: erratum 2," J. Opt. Soc. Am. A 11, 2159-2159 (1994)

This Article is brought to you for free and open access by the Department of Electrical Engineering at ScholarWorks@UNO. It has been accepted for inclusion in Electrical Engineering Faculty Publications by an authorized administrator of ScholarWorks@UNO. For more information, please contact scholarworks@uno.edu. 


\title{
Direct relation between Fresnel's interface reflection coefficients for the parallel and perpendicular polarizations: erratum 2
}

\author{
R. M. A. Azzam \\ Department of Electrical Engineering, University of New Orleans, New Orleans, Louisiana 70148 \\ Received November 16, 1993; accepted March 9, 1994 \\ The record is set straight concerning two equations that determine the reflection phase shifts at a single \\ interface from the intensity reflectances for $p$ - and $s$-polarized light at one angle of incidence. These equations \\ appeared previously in this journal [J. Opt. Soc. Am. 69, 1007 (1979); erratum, J. Opt. Soc. Am. 70, 261
} (1980)].

Previously in this journal ${ }^{1}$ I presented equations that determine explicitly the phase shifts $\delta_{p}$ and $\delta_{s}$ that a monochromatic plane wave of light experiences on reflection at the planar interface between an isotropic transparent medium of incidence and an isotropic absorbing medium of refraction for the linear polarizations parallel $(p)$ and perpendicular $(s)$ to the plane of incidence in terms of the corresponding intensity reflectances $R_{p}$ and $R_{s}$, as measured at one angle of oblique incidence $\phi$. In particular, in Ref. 1, Eq. (18) gives $\delta_{s}$, and Eq. (20) then gives $\Delta=\delta_{p}-\delta_{s}$. A subsequently published erratum ${ }^{2}$ changed both equations. The objective of this note is to indicate that the originally published version of Eq. (18) (in Ref. 1) is correct and that the amended version of Eq. (20) (in Ref. 2) is the correct one. For ease of reference the correct equations are reproduced here:

$$
\begin{aligned}
\cos \delta_{s} & =\frac{\left(R_{s}{ }^{2}-R_{p}\right)+R_{s}\left(1-R_{p}\right) \cos ^{2} 2 \phi}{2 R_{s}{ }^{1 / 2}\left(R_{s}-R_{p}\right) \cos 2 \phi}, \\
\tan \Delta & =\frac{R_{s}{ }^{1 / 2} \sin \delta_{s} \sin ^{2} 2 \phi}{R_{s}{ }^{1 / 2} \cos \delta_{s}\left(1+\cos ^{2} 2 \phi\right)-\left(1+R_{s}\right) \cos 2 \phi} .
\end{aligned}
$$

I am grateful to F. J. J. Clarke for alerting me to the correct forms of these equations.

\section{REFERENCES}

1. R. M. A. Azzam, "Direct relation between Fresnel's interface reflection coefficients for the parallel and perpendicular polarizations," J. Opt. Soc. Am. 69, 1007-1016 (1979).

2. R. M. A. Azzam, "Direct relation between Fresnel's interface reflection coefficients for the parallel and perpendicular polarizations: erratum," J. Opt. Soc. Am. 70, 261 (1980). 